\title{
Peritoneal Membrane Transport Characteristics in Uni-PET with Preceding Icodextrin Dwell as Compared to Classic PET with Preceding Glucose Dwell: A Prospective Study
}

\author{
Gaurav Vohra \\ Army Command Hospital, Chandimandir, India \\ Email: cooldoc1978@rediffmail.com
}

How to cite this paper: Vohra, G. (2021) Peritoneal Membrane Transport Characteristics in Uni-PET with Preceding Icodextrin Dwell as Compared to Classic PET with Preceding Glucose Dwell: A Prospective Study. Open Journal of Nephrology, 11, 516-522.

https://doi.org/10.4236/ojneph.2021.114044

Received: October 16, 2021

Accepted: December 27, 2021

Published: December 30, 2021

Copyright $\odot 2021$ by author(s) and Scientific Research Publishing Inc. This work is licensed under the Creative Commons Attribution International License (CC BY 4.0).

http://creativecommons.org/licenses/by/4.0/

(c) (i) Open Access

\begin{abstract}
Background: In subjects on CAPD who use icodextrin for long night dwell, it has been recommended that nocturnal exchange be replaced by dextrose dwell whenever PET is to be performed as preceding exchange with icodextrin temporarily increases peritoneal membrane permeability and therefore, gives high $\mathrm{D} / \mathrm{PCr}$ and low $\mathrm{D} / \mathrm{D}_{0}$ glucose values. Whether this temporary change is also seen with use of Uni-PET (which involves one hour dwell of $1.5 \%$ dextrose followed by 4 -hour dwell of $4.25 \%$ dextrose) is not known. Methods: In this self, controlled study, subjects on CAPD, who were using icodextrin for long nocturnal dwell for at least 3 months, were screened for enrolment. Pregnancy or lactation, history of any PD related infectious complication in the past one month, present or past malignancy, and poor functional status were exclusion criteria. Enrolled subjects underwent classic PET with preceding $2.5 \%$ dextrose long nocturnal dwell on day 1 followed by Uni-PET with preceding $7.5 \%$ icodextrin long nocturnal dwell on day 2. Difference in $\mathrm{D} / \mathrm{PCr}$ and $\mathrm{D} / \mathrm{D}_{0}$ glucose between the two PETs was primary objectives. The study was approved by Institute Ethics Committee. Results: 15 out of 26 screened subjects were enrolled over a period of 18 months (July 2015-December 2016). The mean $( \pm S D)$ age of study population was $60.8 \pm 9.1$ years. Majority were males and diabetes was the most common cause of CKD. Mean D/PCr were $0.68 \pm 0.11$ and $0.64 \pm 0.08$ in classic PET and Uni-PET, respectively. The difference between the two values was not significant [mean difference between D/PCr (classic PET-Uni-PET): $0.040 \pm 0.86 ; 95 \%$ CI (-0.007 to 0.088); $\mathrm{p}=0.09]$. Similarly, $\mathrm{D} / \mathrm{D}_{0}$ glucose between classic PET and Uni-PET was also similar [mean difference between $\mathrm{D} / \mathrm{D}_{0}$ glucose (classic PET-Uni-PET): -0.02 $\pm 0.09 ; 95 \%$ CI $(-0.06$ to 0.03$) ; p=0.448]$. Conclusion: Peritoneal membrane small solute transport characteristics in Uni-PET with preceding icodextrin
\end{abstract}


dwell are similar to classic PET with preceding glucose dwell. If Uni-PET is used, it may not be necessary to replace preceding nocturnal exchange of icodextrin with that of dextrose as is currently advised.

\section{Keywords}

Icodextrin, Peritoneal Membrane, Peritoneal Equilibration Test, Peritoneal Dialysis Fluid, Peritoneal Dialysis

\section{Introduction}

Peritoneal equilibration test (PET) is a semi-quantitative assessment of peritoneal membrane transport function in patients on peritoneal dialysis [1] [2] [3]. This test was developed by Twardowski et al. in 1987. The PET test is based on the principle that the concentration of the solutes present in the blood, but not initially in the dialysis fluid, will tend to equilibrate with that of the dialysate, after a varying period of time. This equilibration rate can be used to classify patients into transporter categories. The classical PET test lasts for 4 hours, with solution containing glucose at $2.5 \%$ concentration, which evaluates the ratio of solutes in dialysate solution and plasma or fresh glucose solution. Emerging evidence suggests Icodextrin is iso-osmotic peritoneal dialysis fluid (PDF) that may be less damaging to the peritoneal membrane than glucose-based dialysates [4] [5] [6]. Icodextrin is a polymer in which molecules of glucose are linked by alpha $(1-4)$ bonds. It is derived from hydrolysis of corn starch, and has average molecular weight of 16,000 daltons approx. It is available commercially as a $7.5 \%$ solution with lactate as buffer; the solution is isosmotic to normal plasma and exerts oncotic pressure across peritoneum to induce ultrafiltration; Icodextrin does not get absorbed across peritoneal barrier but removed slowly by lymphatics. It is used in a single exchange during night dwell in patients with inadequate ultrafiltration with dextrose based solutions for Continuous Ambulatory Peritoneal Dialysis (CAPD). Also, using Icodextrin solution, increased D/P ratios of creatinine and phosphate even after a dwell time of 6 hours were found compared with an exchange of similar duration using $1.36 \%$ glucose solution [7]. Although no morphologic change in peritoneal blood vessels occurred, certain negative effects in patients who used Icodextrin dialysis solution have been noted [8] [9]. Although most of the values pertaining to peritoneal membrane characteristics may be ascertained using classic PET, few characteristics like sodium sieving, free water transport and osmotic conductance need modified tests like Modified PET, Mini PET, Double Mini PET and Uni-PET (Uni-Peritoneal Equilibration Test).

\section{Objectives}

Primary objective of study was to find difference in $\mathrm{D} / \mathrm{P}_{\text {Creat }}$ (Ratio between dialysate Creatinine concentration at the end of the test and Creatinine concen- 
tration in the plasma)with Uni-PET (with temporary drain) with preceding $7.5 \%$ icodextrin 10 hour dwell versus classic PET (2.5\% dextrose) with preceding 2.5\% dextrose 10 hour dwell in patients on CAPD. Secondary objective was to find difference in $\mathrm{D} / \mathrm{D}_{0}$ glucose(Ratio between dialysate glucose concentration at the end of test and fresh glucose solution) with Uni-PET (with temporary drain) with preceding $7.5 \%$ icodextrin 10 hour dwell versus classic PET (2.5\% dextrose) with preceding $2.5 \%$ dextrose 10 hour dwell in patients on CAPD (Continuous Ambulatory Peritoneal Dialysis).

\section{Study design}

A Prospective diagnostic test study was conducted in peritoneal dialysis care unit, Department of Nephrology, PGIMER, Chandigarh.

Inclusion criteria: 1) Age between 18 - 70 years, 2) On CAPD as peritoneal dialysis modality, 3 ) Use of $7.5 \%$ icodextrin for the daily long night dwell for $\geq 3$ months.

Exclusion criteria: 1) Pregnancy and lactation, 2) History of any PD related Infectious complication in last 1 month, 3) Active malignancy, 4) Poor functional status (NYHA functional class 3 or 4 as shown in Figure 1). Patients were enrolled from August 1, 2016 to December 31, 2017. All patients provided written informed consent.

Each subject was admitted for at least 3 days in the PD care unit for the purpose of this study. At baseline (day 1), routine hematological and biochemical investigations were done for every patient. The patient used 2.5\% dextrose based PD solution for the long night dwell of 10 hours on day 1 of admission. Thereafter, on day 2 of admission, a 4 hour classic PET with 2.5\% dextrose solution was done. The patient used 7.5\% icodextrin based PD solution for the long night dwell of 10 hours on day 2 of admission. On day 3 of admission, a 5 hour Uni-PET (with temporary drain) was done. 2.5\% dextrose classic PET was used as reference test. Descriptive statistics were used to describe characteristics of the study population, change in $\mathrm{D} / \mathrm{P}$ creat and $\mathrm{D} / \mathrm{D}_{0}$ glucose was compared using student $\mathrm{T}$ test, all $\mathrm{P}$ values were two tailed and significant when $<0.05$. As this was a pilot study investigating the result of Uni-PET as compared to classic PET, no formal sample size calculation was required.

\section{Results}

102 cases were assessed for eligibility, and 15 participants were recruited, Mean age of patients was $60.8 \pm 9.1$ years, $66.7 \%$ were males (Table 1 ). Mean $\mathrm{D} / \mathrm{P}_{\text {Creat. }}$ was $0.68 \pm 0.11$ and $0.64 \pm 0.08$ in classic PET and Uni-PET, respectively. The difference between the two values was not significant [mean difference between $\mathrm{D} / \mathrm{P}_{\text {Creat. }}$ (classic PET-Uni-PET): $0.040 \pm 0.86 ; 95 \%$ CI $(-0.007$ to 0.088$) ; \mathrm{p}=$ $0.09]$. $\mathrm{D} / \mathrm{D}_{0}$ at the end of test was more in $7.5 \%$ icodextrin Uni-PET $(0.34 \pm 0.12)$ as compared to $2.5 \%$ dextrose classic PET $(0.33 \pm 0.11)$ (Table 2) and (Figure 2). Number of fast and slow transporters was more with classic PET as compared to Uni-PET. 
Additional outcomes with Uni-PET were mean sodium sieving of $6.7 \pm 3$ $\mathrm{mmol} / \mathrm{L}$, mean free water transport of $122.4 \pm 65.9 \mathrm{~mL}$ and mean osmotic conductance of glucose of $9.1 \pm 10.8 \mu \mathrm{l} / \mathrm{min} / \mathrm{mmHg}$.

\section{Patients eligible for screening (Paients $\mathrm{n}$ long term peritoneal dialysis} during study period) $n=102$

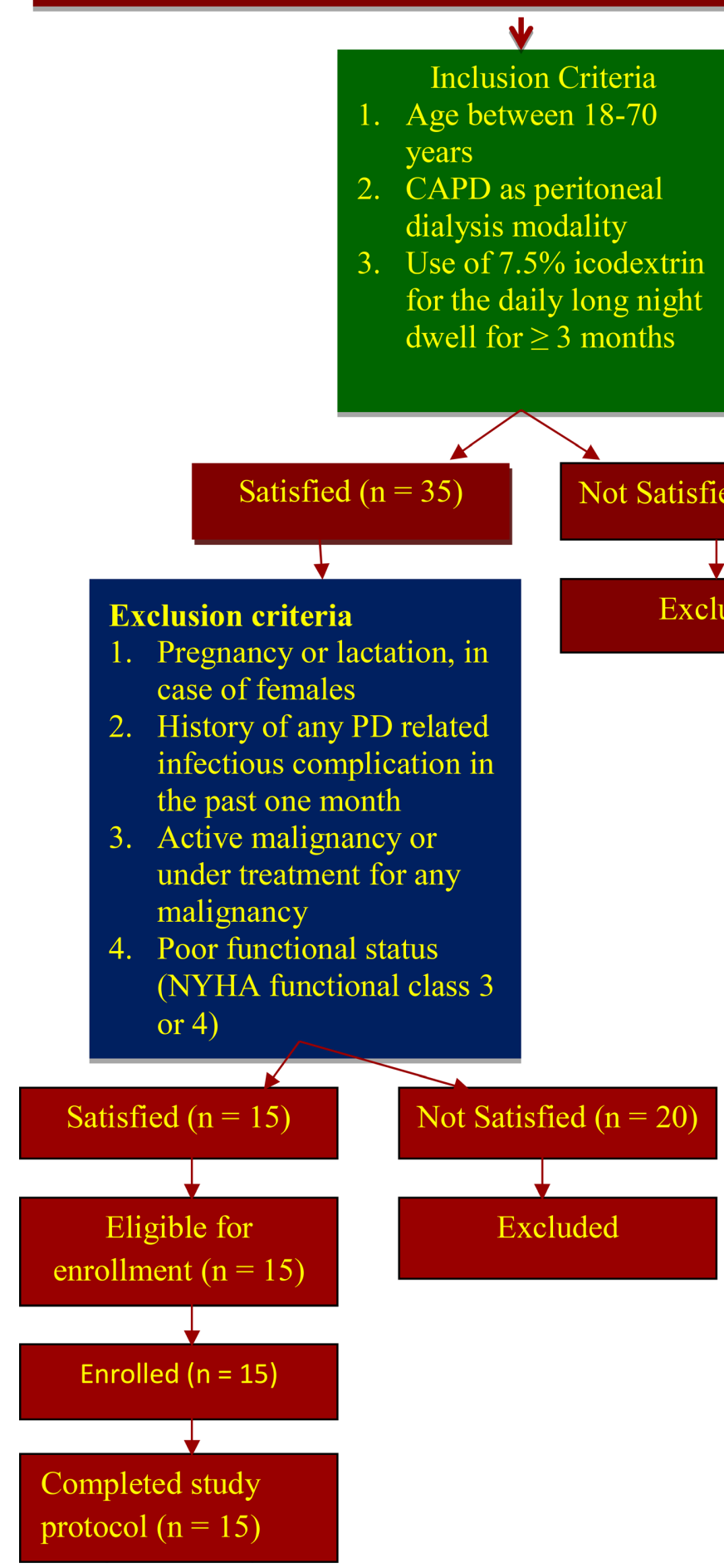

Figure 1. Consort diagram. 
Table 1. Baseline characteristics of patients.

\begin{tabular}{|c|c|}
\hline Characteristics & $\mathrm{f}(\%) /$ Mean $\pm \mathrm{SD}$ \\
\hline Age (years) & $60.8 \pm 9.1$ \\
\hline \multicolumn{2}{|l|}{ Gender } \\
\hline Male & $10(66.7)$ \\
\hline Female & $05(33.3)$ \\
\hline Duration of being on dialysis (months) & $44.2 \pm 38$ \\
\hline Duration of CAPD (months) & $37.2 \pm 32.4$ \\
\hline Duration of icodextrin use (months) & $34.0 \pm 30.6$ \\
\hline Average 24 hrs urine output $(\mathrm{ml})$ & $184 \pm 194.8(0-500)$ \\
\hline Average 24 hrs Ultrafiltration (ml) & $1070 \pm 352.4$ \\
\hline \multicolumn{2}{|l|}{ Blood pressure } \\
\hline Systolic BP (mmHg) & $146.5 \pm 15.5$ \\
\hline Diastolic BP (mmHg) & $87.6 \pm 7.5$ \\
\hline Hemoglobin (gm\%) & $10 \pm 0.9$ \\
\hline \multicolumn{2}{|l|}{ Blood sugar (mg/dl) } \\
\hline Fasting blood glucose (mg/dl) & $111 \pm 15$ \\
\hline Post Prandial Blood Glucose (mg/dl) & $181.5 \pm 29.4$ \\
\hline Serum urea $(\mathrm{mg} / \mathrm{dl})$ & $103 \pm 24.3$ \\
\hline Serum creatinine (mg/dl) & $7.0 \pm 3.2$ \\
\hline Serum albumin $(\mathrm{gm} / \mathrm{dl})$ & $3.2 \pm 0.4$ \\
\hline Serum calcium (mg/dl) & $8.8 \pm 0.27$ \\
\hline Serum phosphorus (mg/dl) & $5.7 \pm 0.78$ \\
\hline Serum sodium (mg/dl) & $140 \pm 3.6$ \\
\hline Serum potassium (mg/dl) & $3.9 \pm 0.3$ \\
\hline Total cholesterol (mg/dl) & $176 \pm 19.4$ \\
\hline
\end{tabular}

Table 2. Comparison of PET variables between 2.5\% dextroseclassic PET and 7.5\% Icodextrin Uni-PET.

\begin{tabular}{|c|c|c|c|c|c|c|}
\hline \multirow{3}{*}{ Variables } & $2.5 \%$ dextrose & $7.5 \%$ icodextrin & \multicolumn{3}{|c|}{ Paired differences } & \multirow{3}{*}{$\begin{array}{l}\mathrm{t} \text {-value } \\
\text { (p-value) }\end{array}$} \\
\hline & \multirow{2}{*}{ Mean \pm SD } & \multirow{2}{*}{ Mean \pm SD } & \multirow{2}{*}{ Mean \pm SD } & \multicolumn{2}{|c|}{$95 \%$ confidence interval } & \\
\hline & & & & Lower & Upper & \\
\hline $\begin{array}{l}\text { Total volume drained after } \\
\text { overnight dwell }(\mathrm{mL})\end{array}$ & $2526.6 \pm 292$ & $2766.6 \pm 336.7$ & $-240 \pm 156.5$ & -326.66 & -153.35 & $-5.94(<0.001)$ \\
\hline $\mathrm{D} / \mathrm{P}_{\text {Creat }}$ at the end of test & $0.68 \pm 0.11$ & $0.64 \pm 0.08$ & $0.040 \pm 0.86$ & -0.007 & 0.088 & $1.7(0.09)$ \\
\hline D/Do glucose at the end of test & $0.33 \pm 0.11$ & $0.34 \pm 0.12$ & $-0.02 \pm 0.09$ & -0.06 & 0.03 & $0.781(0.448)$ \\
\hline $\begin{array}{l}\text { Total Ultrafiltration drained } \\
\text { at the end of test }(\mathrm{mL})\end{array}$ & $236.6 \pm 138$ & $453.3 \pm 192$ & $-216.67 \pm 195.18$ & -324.75 & -108.58 & $0.338(0.001)$ \\
\hline
\end{tabular}




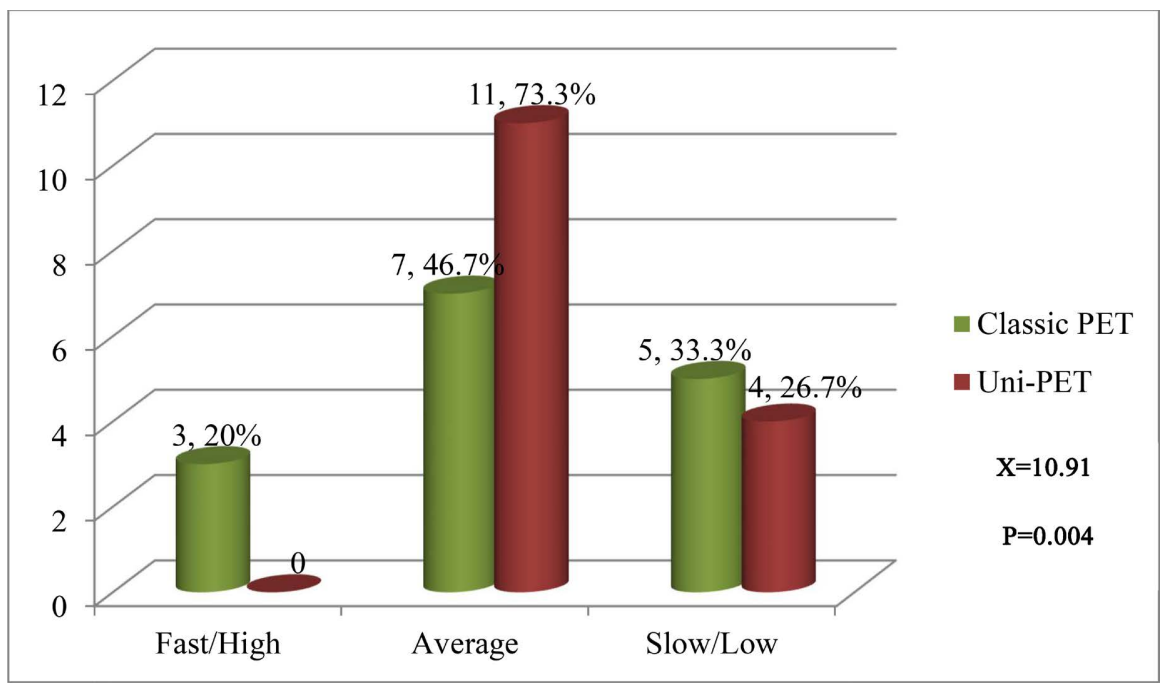

Figure 2. Comparison of transport status of peritoneal membrane based on $\mathrm{D} / \mathrm{P}_{\text {Creat }}$ between Uni-PET and classic PET.

\section{Discussion}

When PET was performed after the preceding dwell with icodextrin solution, peritoneal transport rates of creatinine, phosphate and glucose increased faster compared with PET performed with $1.5 \% / 2.5 \%$ glucose solution night dwell [10]. Possible reasons elucidated were that despite draining the exchange volume completely a part of icodextrin remaining in the peritoneal cavity as residual volume after night dwell got mixed with the PET fill volumes leading to some additional colloid osmotic action along with significantly greater $\mathrm{D} / \mathrm{P}$ ratio of creatinine during PET post icodextrin night dwell. Another reason may be transient subclinical perotoneal membrane inflammation induced by exposure to icodextrin which increases the cytokines IL-6, TNF, and prostaglandins leading to increased peritoneal transport of small solutes.

In patients using icodextrin night dwell even flushing the peritoneal cavity twice with $2.5 \%$ glucose solution before PET did not change the peritoneal membrane characteristics and there was increased $\mathrm{D} / \mathrm{P}_{\text {Creat }}$. This observation suggests that increased membrane permeability charaterstics are not just due to residual volume of icodextrin or transient inflammation. 1.5\% dextrose for 1 hour, done as the first step of Uni-PET probably nullifies the effect of residual volume of icodextrin and transient inflammation triggered by icodextrin night dwell, which is why probably in this study $\mathrm{D} / \mathrm{P}_{\text {creat }}$ was almost similar in both the groups.

This study also showed that there was no significant difference in $\mathrm{D} / \mathrm{D}_{0}$ glucose between Uni-PET with preceding 7.5\% icodextrin 10 hour dwell and classic PET with preceding $2.5 \%$ dextrose 10 hour dwell in patients on CAPD. Although the mechanisms of these events are unclear, the results suggest that icodextrin induces intraperitoneal inflammation.

In peritoneal dialysis subjects using icodextrin, peritoneal membrane small solute transport characteristics in Uni-PET with preceding icodextrin dwell are 
similar to classic PET with preceding glucose dwell. If Uni-PET is used, it may not be necessary to replace preceding nocturnal exchange of icodextrin with that of dextrose as is currently advised.

\section{Conclusion}

In patients using CAPD as modality for renal replacement therapy and using Icodextrin dialysate solution for night dwell, peritoneal membrane small solute transport characteristics in Uni-PET with preceding Icodextrin dwell are similar to Classic PET with preceding glucose dwell. If Uni-PET is used, it may not be necessary to replace preceding nocturnal exchange of Icodextrin with that of dextrose.

\section{Conflicts of Interest}

The author declares no conflicts of interest regarding the publication of this paper.

\section{References}

[1] Twardowski, Z.J., Nolph, K.O., Khanna, R., Prowant, B.F., Ryan, L.P., Moore, H.L., et al. (1987) Peritoneal Equilibration Test. Peritoneal Dialysis International, 7, 138-148. https://doi.org/10.1177/089686088700700306

[2] Pannekeet, M.M., Imholz, A.L.T., Strujik, D.G., Koomen, G.C.M., Langedijk, M.J., Schouten, N., et al. (1995) The Standard Peritoneal Permeability Analysis: A Tool for the Assessment of Peritoneal Permeability Characteristics in CAPD Patients. Kidney International, 48, 866-875. https://doi.org/10.1038/ki.1995.363

[3] Teitelbaum, I. and Burkart, J. (2003) Peritoneal Dialysis. American Journal of Kidney Diseases, 42, 1082-1096. https://doi.org/10.1016/j.ajkd.2003.08.036

[4] Coles, G.A. (1999) Biocompatibility and New Fluids. Peritoneal Dialysis International, 19, S267-S270. https://doi.org/10.1177/089686089901902S44

[5] Garcia-Lopez, E., Lindholm, B. and Tranaeus, A. (2000) Biocompatibility of New Peritoneal Dialysis Solutions: Clinical Experience. Peritoneal Dialysis International, 20, S48-S56. https://doi.org/10.1177/089686080002005S09

[6] Chung, S.H., Stenvinkel, P., Bergstrom, J. and Lindholm, B. (2000) Biocompatibility of New Peritoneal Dialysis Solutions: What Can We Hope to Achieve? Peritoneal Dialysis International, 20, S57-S67. https://doi.org/10.1177/089686080002005S10

[7] Moriishi, M., Kawanishi, H. and Watanabe, H. (2004) Correlation between Peritoneal Permeability and Ultrafiltration Volume with Icodextrin-Based Peritoneal Dialysis Solution. Advances in Peritoneal Dialysis, 20, 166-169.

[8] Parikova, A., Zweers, M.M., Struijk, D.G. and Krediet, R.T. (2003) Peritoneal Effluent Markers of Inflammation in Patients Treated with Icodextrin-Based and Glucosebased Dialysis Solutions. Advances in Peritoneal Dialysis, 19, 186-190.

[9] Martikainen, T.A., Teppo, A.M., Gronhagen-Riska, C. and Ekstrand, A.V. (2005) Glucose Free Dialysis Solutions: Inductors of Inflammation or Preservers of Peritoneal Membrane? Peritoneal Dialysis International, 25, 453-460. https://doi.org/10.1177/089686080502500509

[10] Lilaj, T., Dittrich, E., Puttinger, H., Schneider, B., Haag-Weber, M., Horl, W.H., et al. (2001) A Preceding Exchange with Polyglucose versus Glucose Solution Modifies Peritoneal Equilibration Test Results. American Journal of Kidney Disease, 38, 118-126. https://doi.org/10.1053/ajkd.2001.25204 